\title{
The VAlue OF Non-BINDING ANNOUNCEMENTS IN PUBLIC GOODS EXPERIMENTS SOME THEORY AND EXPERIMENTAL EVIDENCE
}

\author{
MICHAEL BERLEMANN \\ MARCUS DITTRICH \\ GUNTHER MARKWARDT
}

CESIFO WORKING PAPER No. 1352

CAtegory 2: Public Choice

DECEMBER 2004

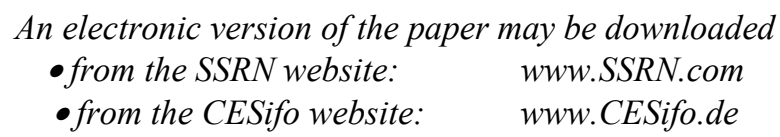




\title{
ThE VALUE OF NON-BINDING ANNOUNCEMENTS IN PUBLIC GOODS EXPERIMENTS SOME THEORY AND EXPERIMENTAL EVIDENCE
}

\begin{abstract}
In this paper we present three simple theoretical models to explain the influence of the possibility to make non-binding announcements on investment behaviour in public goods settings. Our models build on the idea that voluntary contributions to the supply of a public good might be motivated by some form of joy of giving. We show that the possibility to make non-binding announcements has a positive effect on cooperative behaviour, especially if individual announcements and factual investments are communicated to the players after each round. We also show that this result holds true even though the players have an incentive to overstate their true degrees of cooperativeness. Altogether, our theoretical considerations point in the direction that revealing as much information on individual intentions and factual behaviour as possible enhances cooperative behaviour. These conclusions are broadly confirmed by the results of a series of classroom experiments we present.
\end{abstract}

JEL Code: C92, D74, H41.

Keywords: public goods, announcements, joy of giving, experimental economics.

Michael Berlemann

Ifo Institute for Economic Research

Branch Dresden

Einsteinstr. 3

01069 Dresden

Germany

berlemann@ifo.de
Marcus Dittrich

Dresden University of Technology

Faculty of Business Management and

Economics

Chair for Public Economics

01062 Dresden

Germany

marcus.dittrich@mailbox.tu-dresden.de

\author{
Gunther Markwardt \\ Dresden University of Technology \\ Faculty of Business Management and Economics \\ Chair for Public Economics \\ 01062 Dresden \\ Germany \\ gunther.markwardt@mailbox.tu-dresden.de
}

We thank Susanne Mehlhorn, Ken Sennewald, Marcel Thum and Michael Zeidler for useful discussions. The usual disclaimer applies. 


\section{Introduction}

A pure public good is characterized by non-rivalry in consumption and the impossibility or inefficiency of excluding others from its consumption, once it has been supplied. Standard public finance theory suggests that, due to the non-excludability property, a pure public good will not be privately supplied since it is rational to make use of the freerider option. The correction of this sort of market failure is one of the basic normative justifications for government activity. However, some doubts have been raised as to how far the supply of public goods by the government is an optimal solution. It is well known that bureaucracies are subject to x-inefficiencies. Besides, it is far from easy to uncover the public's preferences on the optimal supply of public goods. Even if various methods of revealing the public's preferences have been proposed and discussed, most of them are quite complicated to implement in practice.

When experimental economics started to evolve in the early 1980s the standard theory of public goods was soon subject to experimental studies. Early studies on public goods experiments found that people exhibit significant patterns of cooperative behaviour and thereby contradict the standard theory. This initiated extensive research on the determinants of cooperation in public goods experiments, which is partly theoretical but mostly experimental in nature. Several motives for cooperation have been proposed and discussed. ${ }^{1}$ In the light of the experimental results, the question is raised as to how far the pessimistic view of standard theory, according to which public goods will not be supplied on a private basis, holds true. Moreover, considerable experimental attempts have been made to investigate the means by which cooperation can be further enhanced (for a survey see Ledyard, 1995).

Significant experimental efforts have been made to study the effects of communication on cooperative behaviour. In experiments conducted by Isaac, McCue and Plott (1985), Isaac and Walker (1988) and Brosig, Ockenfels and Weimann (2003), pre-experimental communication increased cooperative behaviour - at least if participants were permitted

\footnotetext{
1 We discuss alternative motives for cooperation in more detail in the second section.
} 
to talk about the game explicitly. Brosig, Ockenfels and Weimann (2003) show the success of coordination efforts to depend significantly on the communication media used. Wilson and Sell (1997) and Berlemann (2003) study the effect of the possibility to make nonbinding announcements and find that the overall degree of cooperation increased in comparison to the case in which no signalling mechanism was available. However, due to the fact that most previous work on the effects of communication on cooperation in public goods settings is more or less experimental in nature, these effects are still not well understood. ${ }^{2}$

This paper aims at contributing to the efforts of understanding the effects of communication on cooperative behaviour by using experimental methods to test formally deduced hypotheses. Relying on Andreoni's (1990) joy of giving argument, we outline a simple theoretical model explaining why rationally acting individuals cooperate in a standard public goods experiment. We then study how the introduction of a strictly limited form of communication influences individual behavior. We therefore extend the basic model for the possibility to make non-binding announcements on future behaviour. It is shown that this form of communication can be supposed to stimulate cooperative behaviour even when there is only aggregate information on cooperation behaviour. However, when information on individual behaviour is revealed, incentives for cooperative behaviour are further increased.

We also report the results of a series of classroom experiments on public goods conducted at Dresden University of Technology in spring 2003. The experimental results broadly confirm our theoretical considerations. While cooperative behaviour remains almost unaffected by non-binding announcements under a low information level, cooperation increases significantly when information on individual behaviour is available. Interestingly enough this holds true although the signalling mechanism is often used for cheating purposes. However, the degree of cheating is significantly lower when information on individual behaviour is available.

\footnotetext{
${ }^{2}$ Brosig, Ockenfels and Weimann (2003), p. 1.
} 


\section{The model}

In the following we first present a simple theoretical framework of a standard public goods experiment in which rational individuals choose a significantly positive investment into the public good. Building up on this basic model we then present three variations of the model with different activity spaces and information levels.

\subsection{The STANDARD PUblic GOOdS SETting}

The standard public goods setting is a finitely repeated game. Due to the finite time horizon of the interaction problem, it can be solved via backward induction. Since there is no room for reputation building in this framework, the interaction problem is the same in each single round. For reasons of simplicity we can therefore suppress time indices in the following.

We assume all individuals $(i=1, \ldots, n)$ to have the same endowment of $w_{i}$ that can be either invested in a private $\left(x_{i}\right)$ or a public good $\left(g_{i}\right)$ :

$$
w_{i}=x_{i}+g_{i}
$$

With $n$ being the number of individuals in the economy and $G_{-i}$ the contribution of all individuals except $i$, the total size of the public good is as follows:

$$
G=\sum_{i=1}^{n} g_{i}=g_{i}+G_{-i}
$$

Monetary utility received from consumption of the two types of goods can be specified by the following individual payoff function:

$$
P_{i}=\alpha \cdot x_{i}+\beta \cdot G
$$

with $\alpha$ and $\beta$ being the marginal returns to the private and public good. Due to the standard assumption $\alpha>\beta$, the dominant strategy is to invest the full endowment into the private good in all rounds - at least when individuals are exclusively interested in maximizing their individual monetary payoffs.

Previous experimental research has shown that in fact individuals invest a significant part of their endowment in the public good (Ledyard, 1995). Several motives for this 
phenomenon have been proposed and discussed, such as the relative payoff position of individuals (Fehr and Schmidt, 1999; Bolton and Ockenfels, 2000), cooperative gain seeking (Brandts and Schram, 1996) and different forms of reciprocity (Rabin, 1993; Falk and Fischbacher, 2000). However, we follow Andreoni (1990) in suggesting that the underlying motivation of cooperative behaviour is some form of impure altruism. According to this view individual utility does not exclusively depend on the consumption of the private and the public good but also on the donations to the public good. Thus, the act of giving itself increases individual utility. Moreover Andreoni and Petrie (2004) argue that individual utility might also depend on the degree of observability of the act of giving. In the following we use the term "joy of giving" to illustrate this phenomenon, which is motivated by the purely egoistic warm glow resulting from making donations. The joy of giving is thus a function $S=S\left(g_{i}\right) .^{3}$

Furthermore, we allow a limited form of communication. In order to do so we assume that individuals can announce how much they intend to invest into the public good. Therefore we model the decision making process in general as a two-stage game. First, individuals announce their intended investment to the public good. After that they decide on their factual contributions.

Let $\hat{g}_{i}$ be the individual announcement of individual $i$. The group announcement $\hat{G}$ can then be written as the sum of announcements of individual $i\left(\hat{g}_{i}\right)$ and all individuals except $i\left(\hat{G}_{-i}\right)$ :

$$
\hat{G}=\sum_{i=1}^{n} \hat{g}_{i}=\hat{g}_{i}+\hat{G}_{-i} .
$$

We assume individual announcements to be non-binding. Moreover, deviations from announcements have no direct impact on the individual payoffs. Nevertheless, it is somewhat likely that even non-binding announcements have an impact on general utility. There are two additional effects that have to be taken into account.

\footnotetext{
${ }^{3}$ Since we argued earlier that observability plays a decisive role for the evolvement of the joy of giving it seems to be appropriate to assume that each individual covers an equal part of the aggregate joy of giving when individual contributions can not be publicly monitored, i.e. $S=S \frac{G}{n}$. In this case, each individual is treated as it would be an average contributor.
} 
A first effect is directly related to Andreoni's (1990) joy of giving argument. Whenever such a joy of giving exists, it is straightforward to assume that the announcement of a donation itself also increases utility. To illustrate this argument imagine a benefactor who is willing to make a donation to finance a public park. It is reasonable to expect that the benefactor's utility rises when the park is opened and he is officially cheered by officials and the press. However, the benefactor's utility also increases when the plan to construct such a park is publicly announced. Thus, it is reasonable to assume that there is a "joy of announcement" besides the joy of giving. We capture the joy of announcement by the function $J=J\left(\hat{g}_{i}\right)^{4}$

A second effect of the announcements on general utility results from the possibility that the player does not stick to his or her previous announcement. For example, the benefactor might decide not to construct the park at all or to contribute less funds than previously announced. In this case he would have to suffer from some form of social ostracism creating disutility for him. ${ }^{5}$ With $A$ being the disutility function, we have $A=A\left(g_{i}-\hat{g}_{i}\right)^{6}$

Altogether, preferences are represented by the general utility function:

$$
U_{i}=U_{i}\left(x_{i}, G, S(G, n), J(\hat{G}, n), A(G, \hat{G}, n)\right)
$$

In order to be able to calculate explicit solutions we assume in the following the joy of giving and the joy of announcement to be linear-quadratic functions of individual donations and announcements, thereby restraining the analysis to the part of the utility function where the marginal utility is non-negative. The disutility from cheating is assumed to be a quadratic function of the difference between announced and factual investments into the

\footnotetext{
4 Analogously to the case of unobservable individual contributions the aggregate joy of announcement has to distributed equally between the $n$ individuals whenever individual announcements remain private information. Thus, we have $J=J \quad \frac{\hat{G}}{n}$ in this case.

${ }^{5}$ A different strand of the literature engages in studying the effects of different pecuniary punishment mechanisms, cf. Fehr and Gchter (2000).

${ }^{6}$ Whenever there is no individual information on announcements and investments only aggregate dishonesty is revealed ex post. Again, the disutility resulting from aggregate cheating has to be borne uniformly by all individuals in this case, e.g. $A=A \frac{G}{n}-\frac{\hat{G}}{n}$.
} 
public good. The intuition for this assumption is that large deviations from announced values are likely to induce more disutility than small ones. ${ }^{7}$

\subsection{Model I: No Announcements possible}

In the first model ("model I") we study the case where there is no possibility to make announcements. Therefore, individuals have no possibility to signal their cooperation. Consequently, they have no joy of announcement and there is also no disutility from social ostracism. Calculating the optimal investment in the public good is straightforward in this case. Using the payoff function and the constraints we can express individual utility as:

$$
U_{i}=\alpha \cdot\left(w_{i}-g_{i}\right)+\beta \cdot\left(g_{i}+G_{-i}\right)+\left[a \cdot \frac{g_{i}+G_{-i}}{n}-b \cdot\left(\frac{g_{i}+G_{-i}}{n}\right)^{2}\right]
$$

with $a$ and $b$ being parameters of the linear-quadratic utility function of the joy of giving. Maximization of $U_{i}$ with respect to $g_{i}$ and assuming identical individuals, i.e. $G=n \cdot g_{i}$, yields the optimal contribution to the public good:

$$
g_{i_{1}}^{*}=(\beta-\alpha) \cdot n+\frac{a}{2 b} .
$$

It is easy to see that the model predicts a positive contribution to the public good, given $a>n \cdot(\beta-\alpha)$ holds true.

\subsection{Model II: Announcements under A LOW information LeVel}

In the second model ("model II") individuals are now able to announce their intended contribution to the public good. As expressed earlier, individuals make non-binding announcements. We further assume that individual announcements remain private information. Only the sum of announcements is communicated to the group before the individuals make their factual investment decisions. Again individual investment decisions remain private information; the individuals are informed about the sum of investments

\footnotetext{
${ }^{7}$ Due to the quadratic disutility function exaggerations of the true degree of cooperativeness are penalized in the same way as understatements. However, the results derived throughout this paper remain unchanged when only overstatements are penalised.
} 
into the public good only ex post. Therefore, we end up with the following utility function for player $i$ :

$$
\begin{aligned}
U_{i}= & \alpha \cdot\left(w_{i}-g_{i}\right)+\beta \cdot\left(g_{i}+G_{-i}\right)+\left[a \cdot \frac{g_{i}+G_{-i}}{n}-b \cdot\left(\frac{g_{i}+G_{-i}}{n}\right)^{2}\right] \\
& +c \cdot\left[a \cdot \frac{\hat{g}_{i}+\hat{G}_{-i}}{n}+b \cdot\left(\frac{\hat{g}_{i}+\hat{G}_{-i}}{n}\right)^{2}\right]-\left(\frac{g_{i}+G_{-i}}{n}-\frac{\hat{g}_{i}+\hat{G}_{-i}}{n}\right)^{2}
\end{aligned}
$$

with $c$ being a scaling parameter allowing the joy of giving and the joy of announcement to differ numerically. In order to identify the optimal announcement and the optimal investment decision, we make use of the backward induction method. At the last stage, individual $i$ chooses $g_{i}$ given his previously made announcement $\hat{g}_{i}$. Substituting player $i$ 's reaction function for $g_{i}$ into the utility function and maximizing with respect to $\hat{g}_{i}$ yields a reaction function for optimal announcements on alternative subsequent investment decisions. Assuming identical individuals, we end up with two independent equations determining the two variables $g_{i}^{*}$ and $\hat{g}_{i}^{*}$. The optimal announcement can thus be determined as:

$$
\hat{g}_{i_{2}}^{*}=\frac{(\beta-\alpha) \cdot n}{2 b \cdot(b c+c+1)}+\frac{a}{2 b}
$$

while the optimal contribution to the public good is:

$$
g_{i_{2}}^{*}=\frac{(\beta-\alpha) \cdot n(b c+1)}{2 b \cdot(b c+c+1)}+\frac{a}{2 b} .
$$

Altogether, model II allows us to deduce two testable hypotheses.

HYPOTHESIS 1. Individual contributions to the public good in model II are higher than in model $I: g_{i_{2}}^{*}>g_{i_{1}}^{*}$.

HYPOTHESIS 2. In model II individual announcements are higher than individual contributions: $\hat{g}_{i_{2}}^{*}>g_{i_{2}}^{*}$.

\subsection{Model III: Announcements under a high information LeVel}

In model III the sequence of actions is as in model II. Unlike model II, we now assume that individuals are supplied with full information on individual announcements and 
investments at the end of the last stage of each round. However, after making their announcements individuals still only get information on the sum of announcements.

In contrast to model II, it is now possible to uncover who stuck to his announcements and who did not, soon after the factual investment decisions have been made. Thus, individuals now have to cover the full consequences of their behaviour when deciding to deviate from their announcements. However, at the time when the announcements are made and the joy of announcements accrues they are private information. The utility function is therefore:

$$
\begin{aligned}
U_{i}= & \alpha \cdot\left(w_{i}-g_{i}\right)+\beta \cdot\left(g_{i}+G_{-i}\right)+\left[a \cdot g_{i}-b \cdot g_{i}^{2}\right] \\
& +c \cdot\left[a \cdot \frac{\hat{g}_{i}+\hat{G}_{-i}}{n}+b \cdot\left(\frac{\hat{g}_{i}+\hat{G}_{-i}}{n}\right)^{2}\right]-\left(g_{i}-\hat{g}_{i}\right)^{2} .
\end{aligned}
$$

Solving for optimal investments and announcements under the assumption of symmetry leads to the optimal announcement:

$$
\hat{g}_{i_{3}}^{*}=\frac{(\beta-\alpha) \cdot n}{2 b \cdot(b c+c+n)}+\frac{a}{2 b}
$$

and the optimal investment into the public good:

$$
g_{i_{3}}^{*}=\frac{(\beta-\alpha) \cdot(b c+n)}{2 b \cdot(b c+c+n)}+\frac{a}{2 b} .
$$

Three testable hypotheses can be derived from model III.

HYPOTHESIS 3. Individual contributions in model III are higher than in model II: $g_{i_{3}}^{*}>g_{i_{2}}^{*}$.

HYPOTHESIS 4. In model III individual announcements are higher than individual contributions: $\hat{g}_{i_{3}}^{*}>g_{i_{3}}^{*}$.

HYPOTHESIS 5. The degree of cheating in model II is higher than in model III:

$\hat{g}_{i_{2}}^{*}-g_{i_{2}}^{*}>\hat{g}_{i_{3}}^{*}-g_{i_{3}}^{*}$. 


\section{Experimental evidence}

In this section we report the results of a small series of classroom experiments we conducted in order to test the implications from the three models described and analysed in the previous section. Since the experiments are naturally quite similar in their basic setups we first explain their common features. We then turn to a presentation of the results of the three different treatments we conducted.

\subsection{BASIC SETUP}

Our data comes from non-computerized classroom experiments with 60 subjects in 12 five-person groups. We conducted three different treatments referring to the three models presented in the previous section and repeated each session three times. Each group took part in one session of the experiments with each session consisting of 10 rounds. The participants were recruited by students of Dresden University of Technology. Most of them (but not all) were students themselves. None of them had taken part in an economics experiment before. Participants were randomly assigned in groups of 5 . The experiments were run at Dresden University of Technology in spring 2003.

Upon arrival participants were placed at different desks in the same room without the possibility of observing the others' actions. Any form of uncontrolled communication during the experimental session was made impossible. The players were asked to read through the written instructions. ${ }^{8}$ Afterwards each participant had the possibility to ask questions. These were answered privately by the experimenter. During the experiment no additional questions were answered. Whenever the students had to act, for instance when revealing their strategies for a certain round, they had to fill out prepared forms that were collected by the experimenter after completion. Participants also had the possibility of writing down the history of the game for their own information. All participants were paid in cash directly after the sessions.

\footnotetext{
8 Translated versions of the instructions are presented in the appendix.
} 
The basic setup of all treatments was as follows: in each of the ten rounds the participants obtained an endowment of 10 tokens which could be either invested into a private or a public good. Each token invested into the private good yielded a private payoff of 4 cents. Each token invested into the public good led to a payoff of 2 cents for each of the 5 participants involved in the session. Thus, the individual payoff of participant $i$ in round $r$ was

$$
P_{i, r}=0.04 \cdot x_{i, r}+0.02 \cdot \sum_{i=1}^{5} g_{i, r}
$$

with $x_{i, r}$ and $g_{i, r}$ being the tokens participant $i$ invested in the private respectively the public good.

The average payoff of the involved 60 players was 6.65 euro (more detailed information on the payoffs is given in table I). No session lasted longer than 30 minutes.

Table I. Payoffs.

\begin{tabular}{lcccc}
\hline & Treatment I & Treatment II & Treatment III & All Treatments \\
\hline Average payoff & & & & \\
Minimum payoff & 6.57 & 6.51 & 6.86 & 6.65 \\
Maximum payoff & 5.44 & 5.08 & 4.56 & 4.56 \\
Standard deviation & 8.44 & 8.42 & 9.16 & 9.16 \\
\hline
\end{tabular}

\subsection{Treatment I}

In his survey of evidence of standard public goods experiments Ledyard (1995, p. 121) reports some stylized facts on players' behaviour. One of the most important findings is that in one-shot as well as in finitely repeated public goods experiments, participants tend to show significantly positive cooperative behaviour but contribute less than Paretoefficient to the public good. This stylized fact is in line with the theoretical models (relevant here: model I) we outlined in the previous section.

In fact, in all four sessions of treatment I there is a significant amount of cooperation (see figure 1). The average contribution to the public good was 4.29 tokens per round 
and subject. In only 12.5 percent $(N=200)$ of all cases the players chose to be free riders and to invest no single token in the public good. Thus, this stylized fact is adequately reproduced in treatment $\mathrm{I}$.

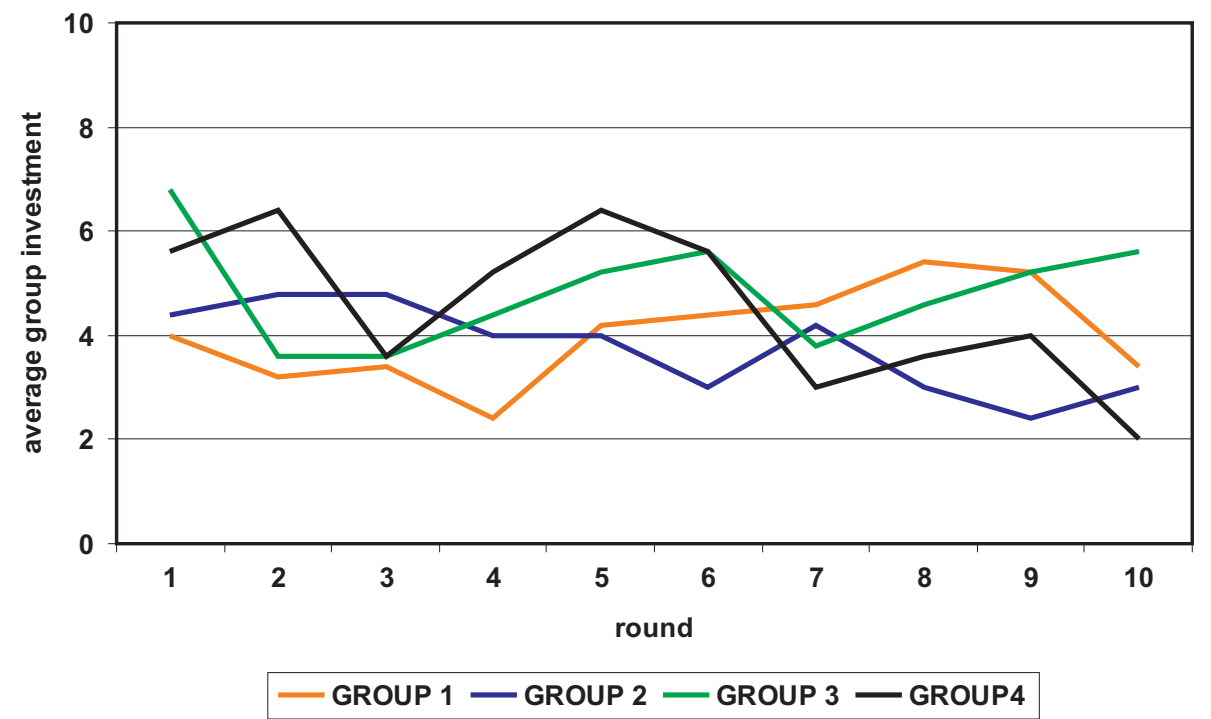

Figure 1. Average contributions to public good in treatment I per group.

There are some further stylized facts that could be observed in standard public goods experiments, e.g. that contributions to the public good decline in the course of finitely repeated games. Often the investments in the public good decline sharply in the last round of the experiment ("last round effect"). However, even in the last round, the investments in the public good are significantly different from zero. While these stylized facts cannot be explained by our theoretical model I, it nevertheless seems to be appropriate to test for these issues since treatment I is intended to serve as a reference scenario. In order to be suitable in this respect, the four sessions of treatment I should coincide with all stylized facts.

Let us first focus on the negative round trend. In fact, contributions to the public good seem to decrease over time. However, in order to detect regularities in the data and study individual investment behaviour we have to apply appropriate empirical methods. Aggregation of individual behaviour is obviously inappropriate when studying individual investment behaviour. Since we focus on individual investment behaviour here, we use 
panel regression methods to evaluate the data for a negative round trend. Most theories trying to explain cooperative behaviour postulate the existence of different types of individuals (Brosig, 2002, p. 276). It is thus highly questionable whether panel regressions with common intercepts are appropriate to make inferences on individual behaviour. These regressions typically have low explanatory power. ${ }^{9}$ We therefore apply fixed effects models to the data, allowing for an individual intercept for every single player rather than a common intercept. ${ }^{10}$ In order to test for a round trend in the data, we run the following fixed effects panel regression (OLS method):

$$
g_{i, r}=c_{i}+\gamma \cdot r+\epsilon_{i, r}
$$

The results, which are reported in table II, ${ }^{11}$ indicate a significant round trend in treatment I. Thus, participants in treatment I significantly decreased their investment into the public good in the course of the game.

Table II. Round trend in treatment I.

\begin{tabular}{|c|c|c|c|c|}
\hline & $\beta$ & T-value & Significance & $r^{2}$ \\
\hline Treatment I & -0.10 & -1.69 & $p<0.10$ & 0.33 \\
\hline
\end{tabular}

We also tested for a last round effect by comparing the investments in round 10 with the investments in the rounds before. The average investment in round 10 (3.50) was 0.88 smaller than the average investments in rounds 1-9 (4.38), a Mann-Whitney ranksum-test reveals that this difference is significant (one sided) at the 90-percent confidence level.

Altogether, the empirical findings underline that treatment I reproduces the stylized facts of standard public goods experiments mentioned earlier quite well. Thus, usage of the results of treatment I as reference scenario seems to be appropriate.

\footnotetext{
${ }^{9}$ See e.g. the study by Wilson and Sell (1997).

10 Due to our relatively scarce number of observations per treatment, we do not run random models as is done e.g. in Neugebauer and Perote (2002).

11 We do not report the fixed effects.
} 


\subsection{TREATMENT II}

In treatment II we changed the design of the standard experiment according to model II. All participants were asked in every single round to announce how many tokens they intend to invest into the public good. The individual announcements were added up and were publicly announced. However, the results of the individual announcements were neither communicated among the participants nor had any influence on the participants' monetary payoff.

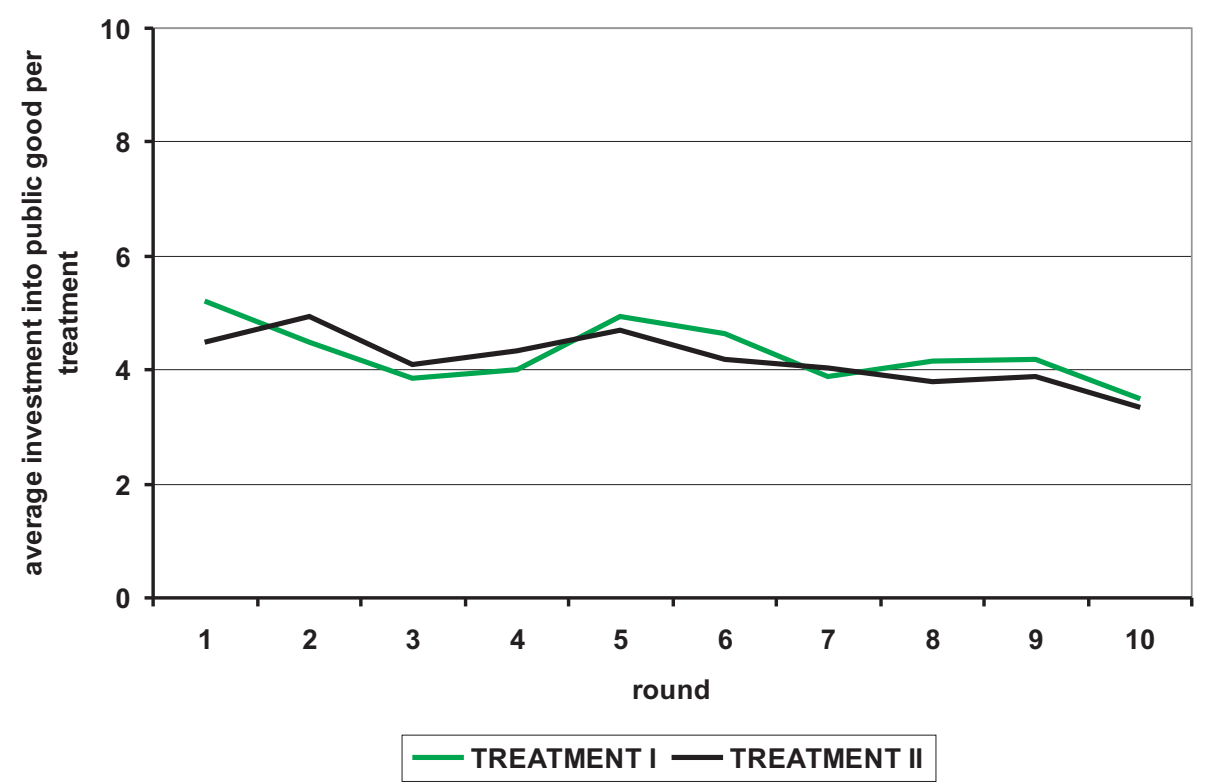

Figure 2. Average contributions to public good in treatment I and II.

Figure 2, which shows the average contributions to the public good in treatment I and in treatment II, indicates that there is no significant difference of cooperative behaviour between the two treatments. To test for hypothesis 1 formally, we compare individual contributions to the public good in treatment I and II (average contribution treatment I: 4.29; average contribution treatment II: 4.19). A Mann-Whitney rank-sum test reveals that the difference is not significant on conventional confidence levels. Thus, we find no supporting evidence for hypothesis $1 .^{12}$

\footnotetext{
12 However, Berlemann (2003) conducted an experiment with exactly the same setting. In contrast to our results he finds a significantly positive effect of the possibility to make non-binding announcements
} 
According to hypothesis 2 we should find, that the players overstate their factual degrees of cooperation. In fact, the players announced an investment of 5.65 tokens in the public good in treatment II while they only invested 4.19 tokens on average. Using a (pairwise) Wilcoxon test this difference is significant on a 99-percent confidence-level. Thus, we find empirical evidence in favour of hypothesis 2 .

\subsection{Treatment III}

The only difference between treatment II and treatment III is that now the players were publicly confronted with their behaviour after each round. After the factual investment decisions were made and the sum of investments were communicated, the players were asked to turn around in order to guarantee intervisibility. Then the individual announcements and factual behaviour were publicly announced. Further communication was prevented.

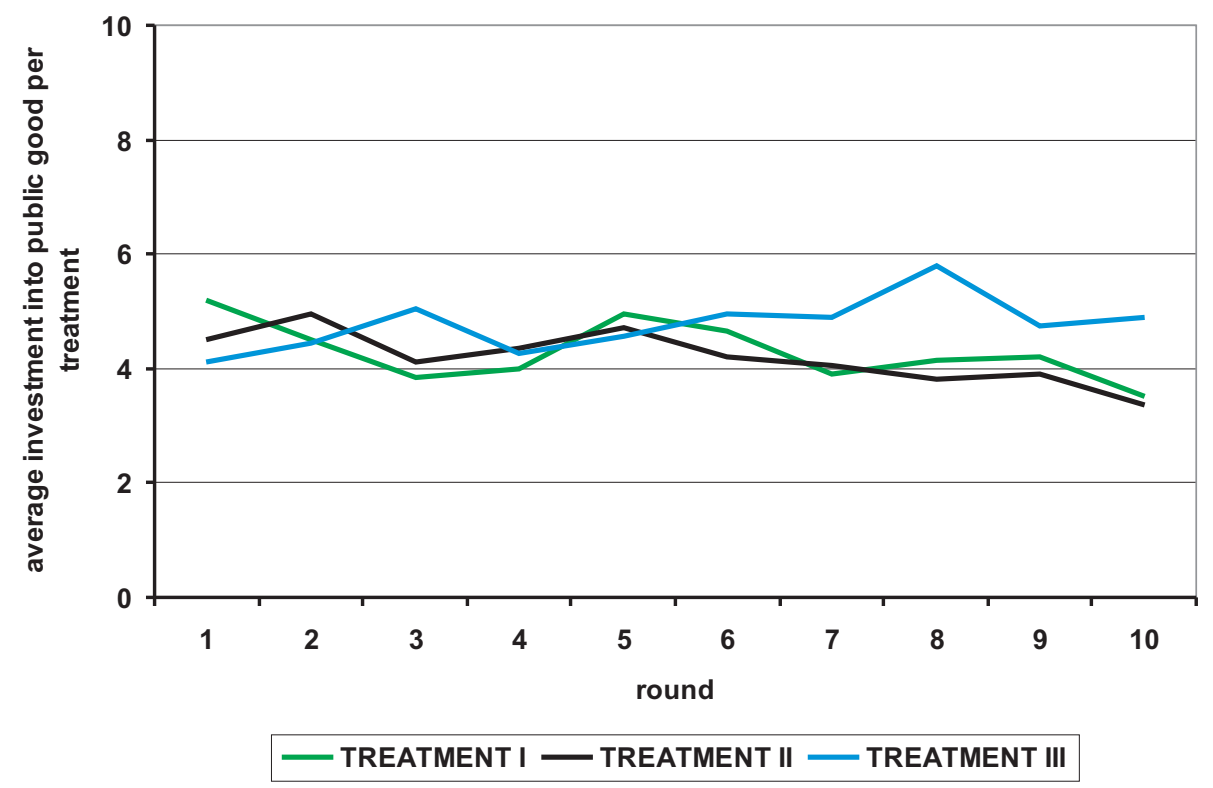

Figure 3. Average contributions to public good in treatment I, II and III.

According to hypothesis 3, the degree of cooperation should increase in treatment III with respect to treatments I and II. Figure 3 indicates that in fact average contributions

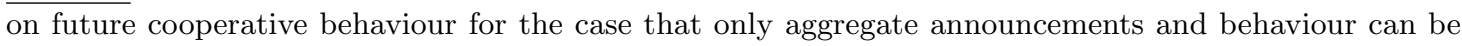
observed. 
to the public good were largest in treatment III. To test for this hypothesis formally we compare the contributions to the public good in treatment III (average contribution: 4.77) with those of treatment II (average contribution: 4.19) and treatment I (average contribution: 4.29). A Mann-Whitney rank-sum test indicates that contributions to the public good were higher in treatment III than in treatment I and II on a 99-percent confidence level. Thus, we find evidence in favour of hypothesis 3 .

Moreover, participants in treatment III should still overstate their investments into the public good (hypothesis 4). A (pairwise) Wilcoxon test indicates the difference between announcements (5.20) and factual investments in the public good (4.77) to be significant on a 99-percent confidence level. Thus, we also find supportive evidence for hypothesis 4 . This is a remarkable result since the players know that they can be perfectly monitored.

However, according to hypothesis 5 , the degree of overstatement should be significantly lower in treatment III than in treatment II. A Mann-Whitney rank-sum test reveals that the average degree of overstatement in treatment III (0.43) is in fact lower than in treatment II (1.46) on a 99-percent confidence level.

We should add that treatment III is quite similar to the experiments conducted and reported by Wilson and Sell (1997). However, while Wilson and Sell made the individual announcements public before the factual investment decision had to be made, we provided this information not before the end of each round. In line with our findings Wilson and Sell find cooperative behaviour to be higher when announcements are possible, at least when information on past individual behaviour is available. Also in line with our results Wilson and Sell find the participants to overstate their true cooperativity.

\section{Conclusions and outlook}

Public goods experiments have a long tradition in both psychology and economics. One of the most striking results of this line of research is that individuals are more cooperative than "pure" theory initially predicted. Consequently, there is nowadays a large literature concerned with the issue of which factors might account for the observed (at least initially) 
surprisingly high level of cooperation. However, a large part of this literature is purely experimental in so far as the influence of various treatment variables on cooperative behaviour is analysed. Rarely do the related papers end up in testable theoretical models.

In this paper we present three simple theoretical models to explain the influence of the possibility of making non-binding announcements on future investment behaviour in public goods settings. Our models build on the idea, first expressed by Andreoni (1990), that voluntary contributing to the supply of a public good might be motivated by some form of joy of giving. We show that the possibility to make non-binding announcements might have a positive effect on cooperative behaviour, especially if individual announcements and factual investments are communicated to the players after each round. We also prove this to be true although the players have an incentive to overstate their true degrees of cooperativeness. Altogether, our theoretical considerations point in the direction that revealing as much information on individual intentions and factual behaviour as possible enhances cooperative behaviour. These results are broadly confirmed by a small series of classroom experiments we reported in this paper.

Somewhat surprisingly, the influence of strictly limited forms of communication such as the possibility of making non-binding announcements on future cooperative behaviour have rarely been studied, yet. This is true with respect to theoretical as well as experimental work. On the one hand, it would be an interesting line of research to study the extent to which the presented theoretical results could be generalized. For example, it would be interesting to extend the model for the cases where (i) even individual announcements are made public before investment decisions are made and (ii) individual announcements are public but individual donations remain private information. On the other hand, it seems to be useful to spend some effort on substantiating our experimental results under more repetitions, varying group sizes and for the two additional treatments just outlined. ${ }^{13}$

\footnotetext{
${ }^{13}$ We should recall the fact that the presented models have clear implications for the influence of the group size on both, announcements and factual investment behaviour.
} 


\section{Appendix}

\subsection{Mathematical DERivations}

\subsubsection{Model II}

Maximising utility (8) with respect to $g_{i}$ yields the reaction function for the optimal contribution to the public good $g_{i}\left(\hat{g}_{i}, G_{-i}, \hat{G}_{-i}\right)$ :

$$
g_{i}=(\beta-\alpha)+\frac{a}{n}-\frac{2 \cdot\left(\left(g_{i}+G_{-i}\right) \cdot(b+1)-\left(\hat{g}_{i}+\hat{G}_{-i}\right)\right)}{n^{2}} .
$$

Substituting $g_{i}$ in the utility function (8) by (16) and maximising $U_{i}$ with respect to $\hat{g}_{i}$ leads to a term expressing individual announcement $\hat{g}_{i}$ in dependence on the announcements of all individuals except $i$ :

$$
\hat{g}_{i}=\frac{n^{2} \cdot(\beta-\alpha)}{2 b \cdot(b c+c+1)}+\frac{n a}{2 b}-\hat{G}_{-i}
$$

Assuming symmetry and therefore substituting $G_{-i}$ by $(n-1) \cdot g_{i}$ and $\hat{G}_{-i}$ by $(n-1) \cdot \hat{g}_{i}$ in (16) and (17) yields the optimal announcement (9). Furthermore, substituting $\hat{g}_{i}$ in (16) by the optimal individual announcement (9) yields the optimal contribution to the public good (10).

\subsubsection{Model III}

Proceedings in model III are similar to model II. Maximising utility (11) with respect to $g_{i}$ yields the following reaction function:

$$
g_{i}=\frac{(\beta-\alpha)+a+2 \hat{g}_{i}}{2 \cdot(b+1)} .
$$

In a next step, we substitute $g_{i}$ in the utility function (11) by (18). Maximising $U_{i}$ with respect to $\hat{g}_{i}$ yields the individual announcement:

$$
\hat{g}_{i}=\frac{n^{2} \cdot(\beta-\alpha)+n a \cdot(b c+c+n)-2 \hat{G}_{-i} b c \cdot(b+1)}{2 b \cdot\left(b c+c+n^{2}\right)} .
$$

Under the assumption of symmetry, (19) yields the optimal announcement (12). Substituting $\hat{g}_{i}$ in (18) by the optimal announcement (12) and solving for $g_{i}$ gives the optimal contribution (13). 


\subsection{EXPERIMENTAL InSTRUCTIONS}

The original instructions are in German. The first part of the instructions were identical for all three treatments. We report this part of the instructions under "General rules of the game". The varying part of the instructions is reported under "Sequence of treatment $N$ " with $N$ being the number of the treatment we refer to.

\subsubsection{General rules of the game}

Five players take part in the experiment. A total of 10 rounds are played. The same rules apply to any round.

At the beginning of each round you receive 10 tokens. In each round you have to decide how you want to use this endowment. There are two alternative investment possibilities: a private investment and a public investment. You can choose between any whole-numbered subdivision.

Each token you invest in the private good yields a private return of 4 cents. In contrast, all players participate of each token invested in the public good. The public good investment generates a cash return of 2 cents per token for all participants. Therefore the payoff $P_{i}$ of player $i$ (per round $r$ ) can be calculated as:

$$
P_{i, r}=0.04 \cdot x_{i, r}+0.02 \cdot \sum_{i=1}^{5} g_{i, r}
$$

with:

- $\quad P_{i}$ : payoff of player $i$

$-x_{i, r}$ : tokens of player $i$ invested in the private good

- $g_{i, r}$ : tokens of player $i$ invested in the public good

It is forbidden to communicate with the other participants throughout the whole experiment. The money you have earned will be paid out immediately after the last round. Your individual payment is not announced publicly. 


\subsubsection{Sequence of treatment I}

In each of the 10 rounds the game follows the same sequential procedure:

1. In each round every player writes on a prepared slip of paper the number of tokens he is willing to invest in the private and in the public good.

2. The experimenter announces how many tokens the whole group has invested in the public good. The individual investment decisions remain confidential.

\subsubsection{Sequence of treatment II}

In each of the 10 rounds the game follows the same sequential procedure:

1. In each round every player writes on a prepared slip of paper the number of tokens he intends to invest in the private and in the public good. This announcement is not binding for following actions.

2. The experimenter announces how many tokens the whole group is intending to invest in the public good. The individual investment intentions remain confidential.

3. Every player writes on a prepared slip of paper the number of tokens he is willing to invest in the private and in the public good.

4. The experimenter announces how many tokens the whole group has invested in the public good. The individual investment decisions remain confidential.

\subsubsection{Sequence of treatment III}

In each of the 10 rounds the game follows the same sequential procedure:

1. In each round every player writes on a prepared slip of paper the number of tokens he intends to invest in the private and in the public good. This announcement is not binding for following actions.

2. The experimenter announces how many tokens the whole group is intending to invest in the public good. The individual investment intentions remain confidential. 
3. Every player writes on a prepared slip of paper the number of tokens he is willing to invest in the private and in the public good.

4. The experimenter announces how many tokens the whole group has invested in the public good. He also announces the initial investment intention of each player as well as his factual investment decision.

\section{References}

Andreoni, J. (1990): Impure Altruism and Donations to Public Goods: A Theory of Warm Glow Giving, Economic Journal 100, 464-477.

Andreoni, J. and R. Petrie (2004): Public Goods Experiments without Confidentiality: A Glimpse into Fund-raising, Journal of Public Economics 88, 1605-1623.

Berlemann, M. (2003): The Effect of Signalling and Beliefs on the Voluntary Provision of Public Goods, Dresden Discussion Papers in Economics 10/03, Dresden University of Technology.

Bolton, G. E. and A. Ockenfels (2000): A Theory of Equity, Reciprocity, and Competition, American Economic Review 90, 166-193.

Brandts, J. and A. Schram (1996): Cooperation and Noise in Public Goods Experiments: Applying the Contributions Function Approach, Journal of Public Economics 79, 399-427.

Brosig, J. (2002): Identifying Cooperative Behaviour: Some Experimental Results in a Prisoner's Dilemma Game, Journal of Economic Behaviour \&3 Organization 47, 257-290.

Brosig, J., A. Ockenfels and J. Weimann (2003): The Effect of Communication Media on Cooperation, German Economic Review 4, 217-241.

Chan, K. S., R. Godby, S. Mestelman and R. A. Muller (2002): Crowding-out Voluntary Contributions to Public Goods, Journal of Economic Behavior $\&$ Organization 48, 305-317.

Falk, A. and U. Fischbacher (2000): A Theory of Reciprocity, Working Paper No. 6, Institute of Empirical Research in Economics, University of Zurich.

Fehr, E. and S. Gchter (2000): Cooperation and Punishment in Public Goods Experiments, American Economic Review 90, 980-994.

Fehr, E. and K. Schmidt (1999): A Theory of Fairness, Competition, and Cooperation, Quarterly Journal of Economics 114, 817-868.

Isaac, R. M., K. F. McCue and C. Plott (1985): Public goods provision in an experimental environment, Journal of Public Economics 26, 51-74.

Isaac, R. M. and J. M. Walker (1988): Communication and free-riding behaviour: the voluntary contribution mechanism, Economic Inquiry 26, 585-608.

Ledyard, J. O. (1995): Public Goods: A Survey of Experimental Research, in: J. Kagel and A. E. Roth (eds.): Handbook of Experimental Economics, Princeton University Press, Princeton/NJ, 111-194. 
Neugebauer, T. and J. Perote (2002): Beliefs, Communication and Feedback Information in Repeated Public Goods Experiments: A Panel Data Analysis, Working Paper, University of York (available under http://www.york.ac.uk/inst/exec/pdf/Beliefs.pdf).

Rabin, M. (1993): Incorporating Fairness into Game Theory and Economics, American Economic Review 83, 1281-1302.

Wilson, R. K. and J. Sell (1997): "Liar, Liar ...". Cheap Talk and Reputation in Repeated Public Good Settings, Journal of Conflict Resolution 41(5), 695-717. 


\section{CESifo Working Paper Series}

(for full list see www.cesifo.de)

1289 Georg Götz and Klaus Gugler, Market Concentration and Product Variety under Spatial Competition: Evidence from Retail Gasoline, September 2004

1290 Jonathan Temple and Ludger Wößmann, Dualism and Cross-Country Growth Regressions, September 2004

1291 Ravi Kanbur, Jukka Pirttilä and Matti Tuomala, Non-Welfarist Optimal Taxation and Behavioral Public Economics, October 2004

1292 Maarten C. W. Janssen, José Luis Moraga-González and Matthijs R. Wildenbeest, Consumer Search and Oligopolistic Pricing: An Empirical Investigation, October 2004

1293 Kira Börner and Christa Hainz, The Political Economy of Corruption and the Role of Financial Institutions, October 2004

1294 Christoph A. Schaltegger and Lars P. Feld, Do Large Cabinets Favor Large Governments? Evidence from Swiss Sub-Federal Jurisdictions, October 2004

1295 Marc-Andreas Mündler, The Existence of Informationally Efficient Markets When Individuals Are Rational, October 2004

1296 Hendrik Jürges, Wolfram F. Richter and Kerstin Schneider, Teacher Quality and Incentives: Theoretical and Empirical Effects of Standards on Teacher Quality, October 2004

1297 David S. Evans and Michael Salinger, An Empirical Analysis of Bundling and Tying: Over-the-Counter Pain Relief and Cold Medicines, October 2004

1298 Gershon Ben-Shakhar, Gary Bornstein, Astrid Hopfensitz and Frans van Winden, Reciprocity and Emotions: Arousal, Self-Reports, and Expectations, October 2004

1299 B. Zorina Khan and Kenneth L. Sokoloff, Institutions and Technological Innovation During Early Economic Growth: Evidence from the Great Inventors of the United States, $1790-1930$, October 2004

1300 Piero Gottardi and Roberto Serrano, Market Power and Information Revelation in Dynamic Trading, October 2004

1301 Alan V. Deardorff, Who Makes the Rules of Globalization?, October 2004

1302 Sheilagh Ogilvie, The Use and Abuse of Trust: Social Capital and its Deployment by Early Modern Guilds, October 2004

1303 Mario Jametti and Thomas von Ungern-Sternberg, Disaster Insurance or a Disastrous Insurance - Natural Disaster Insurance in France, October 2004 
1304 Pieter A. Gautier and José Luis Moraga-González, Strategic Wage Setting and Coordination Frictions with Multiple Applications, October 2004

1305 Julia Darby, Anton Muscatelli and Graeme Roy, Fiscal Federalism, Fiscal Consolidations and Cuts in Central Government Grants: Evidence from an Event Study, October 2004

1306 Michael Waldman, Antitrust Perspectives for Durable-Goods Markets, October 2004

1307 Josef Honerkamp, Stefan Moog and Bernd Raffelhüschen, Earlier or Later: A General Equilibrium Analysis of Bringing Forward an Already Announced Tax Reform, October 2004

1308 M. Hashem Pesaran, A Pair-Wise Approach to Testing for Output and Growth Convergence, October 2004

1309 John Bishop and Ferran Mane, Educational Reform and Disadvantaged Students: Are They Better Off or Worse Off?, October 2004

1310 Alfredo Schclarek, Consumption and Keynesian Fiscal Policy, October 2004

1311 Wolfram F. Richter, Efficiency Effects of Tax Deductions for Work-Related Expenses, October 2004

1312 Franco Mariuzzo, Patrick Paul Walsh and Ciara Whelan, EU Merger Control in Differentiated Product Industries, October 2004

1313 Kurt Schmidheiny, Income Segregation and Local Progressive Taxation: Empirical Evidence from Switzerland, October 2004

1314 David S. Evans, Andrei Hagiu and Richard Schmalensee, A Survey of the Economic Role of Software Platforms in Computer-Based Industries, October 2004

1315 Frank Riedel and Elmar Wolfstetter, Immediate Demand Reduction in Simultaneous Ascending Bid Auctions, October 2004

1316 Patricia Crifo and Jean-Louis Rullière, Incentives and Anonymity Principle: Crowding Out Toward Users, October 2004

1317 Attila Ambrus and Rossella Argenziano, Network Markets and Consumers Coordination, October 2004

1318 Margarita Katsimi and Thomas Moutos, Monopoly, Inequality and Redistribution Via the Public Provision of Private Goods, October 2004

1319 Jens Josephson and Karl Wärneryd, Long-Run Selection and the Work Ethic, October 2004

1320 Jan K. Brueckner and Oleg Smirnov, Workings of the Melting Pot: Social Networks and the Evolution of Population Attributes, October 2004 
1321 Thomas Fuchs and Ludger Wößmann, Computers and Student Learning: Bivariate and Multivariate Evidence on the Availability and Use of Computers at Home and at School, November 2004

1322 Alberto Bisin, Piero Gottardi and Adriano A. Rampini, Managerial Hedging and Portfolio Monitoring, November 2004

1323 Cecilia García-Peñalosa and Jean-François Wen, Redistribution and Occupational Choice in a Schumpeterian Growth Model, November 2004

1324 William Martin and Robert Rowthorn, Will Stability Last?, November 2004

1325 Jianpei Li and Elmar Wolfstetter, Partnership Dissolution, Complementarity, and Investment Incentives, November 2004

1326 Hans Fehr, Sabine Jokisch and Laurence J. Kotlikoff, Fertility, Mortality, and the Developed World's Demographic Transition, November 2004

1327 Adam Elbourne and Jakob de Haan, Asymmetric Monetary Transmission in EMU: The Robustness of VAR Conclusions and Cecchetti's Legal Family Theory, November 2004

1328 Karel-Jan Alsem, Steven Brakman, Lex Hoogduin and Gerard Kuper, The Impact of Newspapers on Consumer Confidence: Does Spin Bias Exist?, November 2004

1329 Chiona Balfoussia and Mike Wickens, Macroeconomic Sources of Risk in the Term Structure, November 2004

1330 Ludger Wößmann, The Effect Heterogeneity of Central Exams: Evidence from TIMSS, TIMSS-Repeat and PISA, November 2004

1331 M. Hashem Pesaran, Estimation and Inference in Large Heterogeneous Panels with a Multifactor Error Structure, November 2004

1332 Maarten C. W. Janssen, José Luis Moraga-González and Matthijs R. Wildenbeest, A Note on Costly Sequential Search and Oligopoly Pricing, November 2004

1333 Martin Peitz and Patrick Waelbroeck, An Economist's Guide to Digital Music, November 2004

1334 Biswa N. Bhattacharyay and Prabir De, Promotion of Trade, Investment and Infrastructure Development between China and India: The Case of Southwest China and East and Northeast India, November 2004

1335 Lutz Hendricks, Why Does Educational Attainment Differ Across U.S. States?, November 2004

1336 Jay Pil Choi, Antitrust Analysis of Tying Arrangements, November 2004

1337 Rafael Lalive, Jan C. van Ours and Josef Zweimueller, How Changes in Financial Incentives Affect the Duration of Unemployment, November 2004 
1338 Robert Woods, Fiscal Stabilisation and EMU, November 2004

1339 Rainald Borck and Matthias Wrede, Political Economy of Commuting Subsidies, November 2004

1340 Marcel Gérard, Combining Dutch Presumptive Capital Income Tax and US Qualified Intermediaries to Set Forth a New System of International Savings Taxation, November 2004

1341 Bruno S. Frey, Simon Luechinger and Alois Stutzer, Calculating Tragedy: Assessing the Costs of Terrorism, November 2004

1342 Johannes Becker and Clemens Fuest, A Backward Looking Measure of the Effective Marginal Tax Burden on Investment, November 2004

1343 Heikki Kauppi, Erkki Koskela and Rune Stenbacka, Equilibrium Unemployment and Capital Intensity Under Product and Labor Market Imperfections, November 2004

1344 Helge Berger and Till Müller, How Should Large and Small Countries Be Represented in a Currency Union?, November 2004

1345 Bruno Jullien, Two-Sided Markets and Electronic Intermediaries, November 2004

1346 Wolfgang Eggert and Martin Kolmar, Contests with Size Effects, December 2004

1347 Stefan Napel and Mika Widgrén, The Inter-Institutional Distribution of Power in EU Codecision, December 2004

1348 Yin-Wong Cheung and Ulf G. Erlandsson, Exchange Rates and Markov Switching Dynamics, December 2004

1349 Hartmut Egger and Peter Egger, Outsourcing and Trade in a Spatial World, December 2004

1350 Paul Belleflamme and Pierre M. Picard, Piracy and Competition, December 2004

1351 Jon Strand, Public-Good Valuation and Intrafamily Allocation, December 2004

1352 Michael Berlemann, Marcus Dittrich and Gunther Markwardt, The Value of NonBinding Announcements in Public Goods Experiments: Some Theory and Experimental Evidence, December 2004 